\title{
Evaluasi Aspek Usability pada Aplikasi Simalu Menggunakan Metode Usability Testing
}

\author{
Ni Luh Putri Ari Wedayanti, Ni Kadek Ayu Wirdiani, I Ketut Adi Purnawan \\ Program Studi Teknologi Informasi, Fakultas Teknik, Universitas Udayana \\ Bukit Jimbaran, Bali, Indonesia, telp. (0361) 701806 \\ e-mail: niluhputri60@gmail.com, ayu wirdi@yahoo.com, adipurnawan@unud.ac.id
}

\begin{abstract}
Abstrak
Tingkat usability dapat mempengaruhi kemudahan penggunaan suatu aplikasi termasuk aplikasi mobile, sehingga penting untuk dilakukanya evaluasi. Aplikasi Simalu merupakan sebuah aplikasi lokal Bali yang bergerak dalam bidang kebersihan lingkungan. Simalu tergolong aplikasi baru karena dirilis pada awal bulan Januari tahun 2018 dan belum pernah dilakukan evaluasi usability sebelumnya. Evaluasi usability dilakukan untuk meningkatkan User Experience pengguna, sehingga aplikasi dapat diterima dan digunakan lebih mudah oleh pengguna. Metode yang digunakan untuk melakukan evaluasi yaitu usability testing dengan teknik Retrospective Think Aloud dan Performance Measurement. Hasil yang didapatkan adalah aplikasi Simalu memiliki kualitas yang belum dapat dikatakan efektif, efisien dan memenuhi kepuasan pengguna, sehingga perbaikan desain juga dilakukan agar aplikasi lebih baik lagi untuk memenuhi harapan pengguna.
\end{abstract}

Kata kunci: Aplikasi Simalu, Evaluasi Usability, User Experience, Usability Testing, Retrospective Think Aloud, Performance Measurement.

\begin{abstract}
The usability level can influence how easy the use of an application including a mobile application, so it is important to perform an evaluation. The Simalu application is Bali's local application that focuses on environmental hygiene. Simalu is classified as a new application as it was released in early January 2018 and has never been evaluated before. Usability evaluation is employed in aim to improve user experience so that the application can be accepted and used more easily by users. The methods applied for the evaluation are usability testing with Retrospective Think Aloud and Performance Measurement techniques. The result shows that the Simalu application has not yet possessed effective and efficient qualities and it also has not yet fulfilled users' satisfaction, so improvements in the design are also required so that the application can better meet the users' expectations.
\end{abstract}

Keywords: Simalu Application, Usability Evaluation, User Experience, Usability Testing, Retrospective Think Aloud, Performance Measurement.

\section{Pendahuluan}

Teknologi informasi di era globalisasi saat ini berkembang dengan pesat sehingga memudahkan masyarakat dalam melakukan aktifitasnya [1]. Smartphone merupakan salah satu contoh perkembangan teknologi informasi yang saat ini sedang berkembang pesat [2]. Smartphone memiliki berbagai macam kemampuan dalam menjalankan berbagai aktivitas dengan mudah untuk mendukung produktifitas [3]. Hasil dari survei Asosiasi Penyelenggara Jasa Internet Indonesia pada tahun 2017, menyatakan bahwa persentase kepemilikian smartphone mencapai 50,08\% dari jumlah populasi penduduk di Indonesia sebesar 262 juta orang. Perkembangan smartphone yang sedang berkembang pesat juga mendorong para developer berlomba-lomba untuk memanfaatkan situasi ini dengan menciptakan aplikasiaplikasi baru yang dapat bermanfaat bagi para penggunanya. Salah satu hal yang harus diperhatikan dalam proses pengembangan aplikasi baru yaitu aspek usability [4]. Penelitian sebelumnya yang berjudul $A$ Conceptual Framework for Measuring the Quality Aspects of Mobile Learning menyatakan bahwa masih banyak aplikasi mobile di pasaran yang sulit untuk digunakan dan dipelajari oleh penggunanya dikarenakan tingkat usability yang rendah. Rendahnya usability dari suatu sistem dapat mempengaruhi keputusan pengguna untuk 
menggunakan aplikasi tersebut secara terus menurus atau dapat beralih menggunakan aplikasi lain [5].

Contoh aplikasi mobile baru yang sedang berkembang adalah aplikasi Simalu. Aplikasi Simalu adalah sebuah aplikasi lokal Bali yang bergerak dalam bidang sosial mengenai kebersihan lingkungan yang dirilis pada awal bulan Januari tahun 2018. Aplikasi Simalu tergolong aplikasi baru yang masih memiliki permasalahan berkaitan dengan aspek usability. Permasalahan yang terjadi yaitu pengguna mengeluhkan sering terjadi eror saat menggunakan aplikasi, fitur yang ditawarkan tidak berfungsi dengan baik, terdapat penempatan fitur yang tidak sesuai dan icon yang digunakan dinilai ambigu sehingga dapat membuat pengguna baru merasa bingung dan memiliki persepsi yang berbeda saat menggunakan aplikasi. Pengujian usability terhadap aplikasi juga belum pernah dilakukan sebelumnya. Pengujian suatu sistem yang baru atau sedang dijalankan perlu dilakukan agar sistem berjalan sesuai dengan fungsionalitas yang diharapkan serta kesalahan maupun kekurangan dapat dideteksi dan diperbaiki sesegera mungkin [6]. Permasalahan berdasarkan yang telah dibahas, agar aplikasi dapat diterima dan digunakan dengan mudah oleh pengguna, maka perlu dilakukan Pengujian usability.

Pengujian dilakukan dengan metode Usability Testing menggunakan standar ISO 924111 yang mengukur variabel efektifitas, efisiensi, dan kepuasan pengguna dalam menggunakan aplikasi Simalu. Teknik yang digunakan yaitu Retrospective Think Aloud (RTA) dan Performance Measurement. Retrospective Think Aloud digunakan karena dapat mengukur kepuasaan pengguna saat menggunakan suatu sistem, Performance Measurement digunakan karena dapat mengukur efektifitas dan efisiensi.

\section{Metodologi Penelitian}

Metodologi penelitian berisi tahapan atau gambaran dari penelitian yang dilakukan. Metodelogi bermanfaat pada setiap penelitian untuk mempermudah mengerjakan penelitian yang dibuat. Metodelogi penelitian yang dibahas meliputi alur penelitian, data, responden penelitian, dan dasar pengembangan rekomendasi perbaikan yang digunakan didalam melakukan penelitian.

\subsection{Alur Penelitian}

Alur penelitian merupakan tahapan atau urutan yang sudah ditetapkan dalam melakukan penelitian. Tahapan penelitian disesuaikan dengan tahapan pada analisis dan evaluasi usability dengan metode usability Testing pada aplikasi Simalu. Alur yang dilakukan dalam proses penelitian ini dapat dilihat pada Gambar 1.

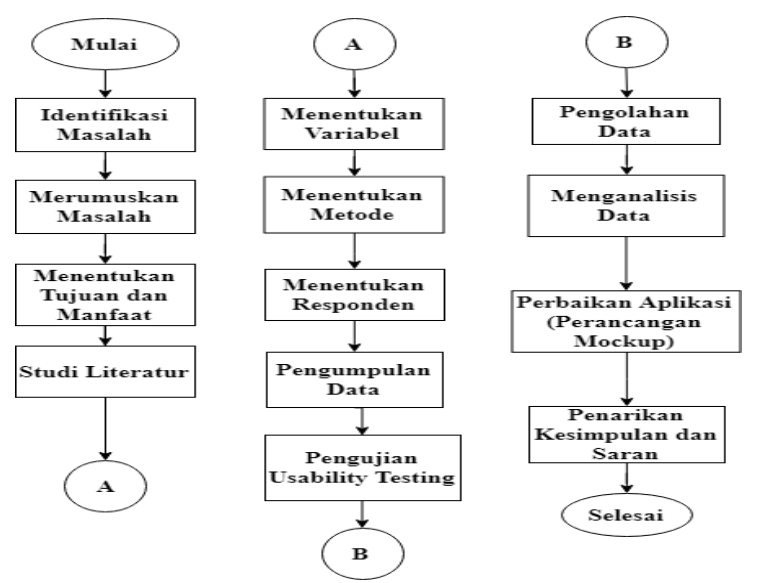

Gambar 1. Alur Penelitian

Alur yang dilakukan dalam proses penelitian meliputi mengidenfikasi masalah, merumuskan masalah, menentukan tujuan dan manfaat, melakukan studi literatur dengan mencari refrensi seperti penelitian terdahulu, menentukan metode pengujian, menentukan responden, melakukan pengumpulan data untuk mendapatkan hasil pengujian, melakukan pengujian, melakukan pengolahan data, menganalisa hasil pengujian, membuat rekomendasi perbaikan, dan selanjutnya menarik kesimpulan. 


\subsection{Data}

Data diperlukan untuk mendukung keberhasilan dari evaluasi yang dihasilkan. Faktor yang perlu diperhatikan dalam melaksanakan penelitian ini yaitu sumber data, jenis data, metode pengumpulan data dan pengolahan data.

a. Sumber Data

Sumber data yang digunakan dalam penelitian ini terdiri dari data primer dan sekunder. Data primer adalah hasil pengujian dari responden terhadap aplikasi Simalu menggunakan metode usability Testing. Data sekunder yaitu bersumber pada studi literatur yang meliputi penelitian terdahulu, jurnal ilmiah, buku, e-book, dan website resmi.

b. Jenis Data

Jenis data yang digunakan dalam penelitian ini terdiri dari data kuantitatif dan kualitatif. Data kuantitatif yaitu hasil dari pengujian usability Testing dengan teknik Performance Measurement. Data kualitatif yaitu hasil dari pengujian usability Testing dengan teknik Retrospective Think Aloud (RTA).

\section{c. Metode Pengumpulan Data}

Metode pengumpulan data yang digunakan dalam melakukan penelitian adalah observasi, task scenario dan wawancara. Observasi yaitu melakukan pengamatan serta melihat dari dekat bagaimana aplikasi digunakan oleh para responden sehingga peneliti dapat mengenalisa permasalahan-permasalahan yang muncul [7]. Pemberian task scenario yaitu merupakan sekumpulan tugas yang harus dikerjakan oleh responden saat menggunakan aplikasi yang akan dievaluasi, serta melakukan wawancara untuk pengumpulan data secara langsung guna memperoleh kedalaman informasi yang dibutuhan.

\section{d. Pengolahan Data}

Data yang telah dikumpulkan pada tahap pengumpulan data selanjutnya diolah. Data yang telah diolah kemudian dilakukan analisis hasil. Pegolahan data dalam penelitan evaluasi aspek usability untuk meningkatkan user experience pada aplikasi Simalu adalah sebagai berikut.

\section{a) Performance Measurement}

Teknik Performance Measurement digunakan untuk mengukur bagaimana keefektifitasan dan keefisiensian aplikasi Simalu saat digunakan oleh pengguna. Pengukuran efektifitas dapat dihitung berdasarkan kesuksesan dan kegagalan task yang telah dikerjakan oleh setiap responden. Efektifitas dihitung dengan menetapkan angka biner "1" jika responden berhasil mengerjakan task dan "0" jika responden gagal. Rumus yang digunakan untuk menghitung tingkat dari keberhasilan responden dapat dilihat pada persamaan (1), sedangkan Rumus yang digunakan untuk menghitung tingkat dari kegagalan responden dapat dilihat pada persamaan (2).

$$
\begin{array}{lll}
\text { Berhasil }= & \frac{\text { Jumlah tugas yang berhasil dilakukan }}{\text { Jumlah total tugas }} \times 100 \% \\
\text { Gagal }= & \frac{\text { Jumlah tugas yang gagal dilakukan }}{\text { Jumlah total tugas }} & \times 100 \%
\end{array}
$$

Rumus untuk menghitung tingkat dari keberhasilan responden yang digunakan yaitu banyaknya tugas yang berhasil dikerjakan dibagi banyaknya total tugas yang diberikan yang hasilnya dikalikan $100 \%$. Rumus untuk menghitung tingkat dari kegagalan responden yang digunakan yaitu banyaknya tugas yang gagal dikerjakan dibagi banyaknya total tugas yang diberikan yang hasilnya dikalikan $100 \%$. Hasil perhitungan dari task berhasil dan gagal nantinya menentukan apakah aplikasi Simalu sudah efektif untuk digunakan, apabila nilai rata-rata task yang dikerjakan berhasil mencapai $100 \%$ maka aplikasi Simalu dapat dikatakan sudah efektif.

Pengolahan data untuk dimensi efisiensi dapat dilakukan dengan memperhitungkan rata-rata waktu responden dalam mengerjakan setiap task yang diberikan dengan satuan detik. Waktu pengerjaan mulai dihitung setelah peneliti selesai membacakan task scenario yang diberikan sampai responden telah selesai mengerjakan task. Hasil perhitungan yang didapat 
nantinya menunjukkan task mana saja yang membutuhkan waktu paling lama untuk diselesaikan berdasarkan rata-rata waktu untuk mengerjakan setiap task dari seluruh responden yang ada [8].

b) Retrospective Think Aloud

Data Retrospective Think Aloud diperoleh dengan melakukan wawancara kepada responden saat melihat ulang hasil video rekaman. Wawancara dilakukan untuk mengetahui pengalaman dan pendapat responden selama menggunakan aplikasi Simalu. Pengolahan data dilakukan dengan megumpulkan hasil verbalisasi pemikiran responden. Verbalisasi tersebut meliputi kesan pesan ataupun kesulitan yang diutarakan responden beserta saran yang diberikan saat sesi pengujian selesai dilaksanakan.

\subsection{Responden Pengujian}

Penelitian ini melibatkan sebanyak 10 orang responden. Pengelompokan responden dibagi menjadi dua kategori yaitu, lima responden kategori pemula adalah masyarakat umum yang termasuk generasi X (1965-1980) dan tidak terbiasa menggunakan aplikasi mobile, dan lima responden kategori trampil adalah android developer dan mahasiswa perguruan tinggi yang termasuk generasi millennials (1981-2000) dan terbiasa menggunakan aplikasi mobile. Pembagian kategori dilakukan untuk melihat bagimana penilaian aplikasi dari sisi dua kategori pengguna yang berbeda.

\subsection{Dasar Pengembangan Rekomendasi Perbaikian}

Dasar penentuan perbaikan yang digunakan untuk memberikan rekomendasi perbaikan aplikasi yaitu berdasarkan pengujian dengan teknik Retrospective Think Aloud. Hasil verbalisasi responden berupa kritik dan saran yang diberikan untuk dijadikan bahan rekomendasi perbaikan. Literatur tambahan juga digunakan sebagai panduan dalam melakukan perbaikan aplikasi Simalu yaitu menggunakan teori The Golden Rules of User Interface Design oleh Ben Shneiderman dan Catherine Plaisant dalam bukunya yang berjudul Designing the User Interface: Strategies for Effective Human Computer Interaction.

\section{Kajian Pustaka}

Kajian pustaka memuat semua pustaka yang dijadikan acuan pada penelitian. Sumbersumber yang digunakan dalam penelitian diperoleh dari buku, internet, maupun jurnal. Kajian pustaka yang dijadikan landasan dalam melakukan penelitian yaitu user experience, usability, metode evaluasi usability, usability testing.

\subsection{User Experience}

User Experience merupakan bentuk interaksi antara manusia dan komputer (Human Computer Interaction) yang meliputi website, aplikasi mobile, dan aplikasi desktop. User Experience berhubungan dengan persepsi atau respon seseorang yang dihasilkan pada saat menggunakan suatu produk [9]. User Experience terdiri dari 4 elemen yang saling tergantung diantaranya adalah Branding, Usability, Functionality, dan Content.

\subsection{Usability}

Usability merupakan bagian dari User Experience. Usability diambil dari kata usable yang berarti tingkatan kualitas dari suatu produk yang mudah digunakan, mudah dipelajari dan mendorong pengguna untuk menggunakannya sebagai alat bantu dalam menyelesaikan tugas [10]. Usability dapat digunakan untuk mengukur kualitas penggalaman pengguna saat berinteraksi dengan sebuah produk seperti website atau aplikasi.

\subsection{Metode Evaluasi Usability}

Metode evaluasi usability yang berfokus pada pengguna dijelaskan oleh Panayiotis Zaphiris dalam bukunya yang berjudul Human Computer Interaction Research in Web Design and Evaluation antara lain meliputi Usability Testing, Usability Inspection, Usability Inquiry, dan Usability Model / Metricsbased. Empat metode Usability yang ada tiap-tiap metode masih memiliki beberapa teknik yang dapat digunakan untuk melakukan evaluasi usability. 


\subsection{Usability Testing}

usability Testing adalah salah satu kategori metode dalam evaluasi usability yang digunkan untuk mengevaluasi sebuah produk dengan mengujinya langsung pada pengguna. Tujuannya adalah untuk mengidentifikai masalah uji ketergunaan seperti, mengumpulkan data kualitatif dan kuantitatif, mengukur kemudahan, mengukur efisiensi dan menentukan kepuasan pengguna dengan produk (usability.gov). 10 teknik dalam metode Usability Testing yang dapat digunakan peneliti untuk melakukan Evaluasi usability meliputi Thinking-Aloud Protocol, Shadowing Method, Co-Discovery Learning, Coaching Method, Question-Asking Protocol, Teaching Method, Restrospective Testing, Performance Measurement, Remote Testing, dan Eye Tracking.

\section{Hasil dan Pembahasan}

Bagian ini menampilkan hasil dari proses pengolahan data pada penelitian. Pengolahan data di dapat dari pengujian dengan menggunakan teknik Performance Measurement dan Retrospective Think Aloud. Data yang telah diolah kemudian dilakukan analisis hasil.

\subsection{Hasil Pengujian}

Hasil pengujian pada bagian ini menampilkan hasil dari proses pengolahan data yang di dapat. Hasil pengolahan data berasal dari pengujian dengan menggunakan teknik Performance Measurement dan Retrospective Think Aloud. Teknik Performance Measurement dan Retrospective Think Aloud menghasilkan tingkat efektifitas, efesiensi dan kepuasan pengguna dalam menggunaka aplikasi.

a. Performance Measurement

Bagian ini menampilkan hasil pengujian menggunakan teknik Performance Measurement. Pengujian dengan menggunakan teknik Performance Measurement digunakan untuk mengukur variabel efektifitas dan efisiensi. Hasil dari proses pengolahan data efektifitas dan efisiensi yang telah di dapat dari pengujian yang telah dilaksanakan adalah sebagai berikut. a) Efektifitas

Pengukuran efektifitas dihitung dari rata-rata nilai berdasarkan kesuksesan dan kegagalan dari 29 task yang dikerjakan oleh 10 responden. Responden telah ditentukan dengan dua kategori yaitu trampil dan pemula. Rata-rata nilai dari task yang berhasil dikerjakan oleh responden kategori trampil dapat dilihat pada Tabel 1.

Tabel 1. Hasil Data Task Berhasil Responden Kategori Trampil

\begin{tabular}{|c|c|c|c|c|}
\hline $\begin{array}{c}\text { Kode } \\
\text { Responden }\end{array}$ & $\begin{array}{c}\text { Jumlah Task } \\
\text { yang Berhasil } \\
\text { dikerjakan }\end{array}$ & Total Tugas & Berhasil & \multirow{2}{*}{ Rata-rata } \\
\hline R1 & 27 & 29 & 93,10 & \multirow{2}{*}{$70 \%$} \\
\cline { 1 - 3 } R2 & 23 & 29 & 79,31 & \\
\hline R3 & 23 & 29 & 79,31 & \\
\hline R4 & 19 & 29 & 65,51 & \\
\hline R5 & 22 & 29 & 75,86 & \\
\hline
\end{tabular}

Tabel 1 merupakan hasil rata-rata nilai dari task yang berhasil dikerjakan oleh 5 responden kategori trampil. Rata-rata nilai yang dihasilkan adalah sebesar $79 \%$. Rata-rata nilai dari task yang gagal dikerjakan oleh responden kategori trampil dapat dilihat pada Tabel 2.

Tabel 2. Data Hasil Task Gagal Responden Kategori Trampil

\begin{tabular}{|c|c|c|c|c|}
\hline $\begin{array}{c}\text { Kode } \\
\text { Responden }\end{array}$ & $\begin{array}{c}\text { Jumlah Task } \\
\text { yang Berhasil } \\
\text { dikerjakan }\end{array}$ & Total Tugas & Berhasil & \multirow{2}{*}{ Rata-rata } \\
\hline R1 & 2 & 29 & 6,89 & \multirow{2}{*}{$\mathbf{2 1 \%}$} \\
\hline R2 & 6 & 29 & 20,68 & \\
\hline R3 & 6 & 29 & 20,68 & \\
\hline R4 & 10 & 29 & 34,48 & \\
\hline R5 & 7 & 29 & 24,13 & \\
\hline
\end{tabular}


Tabel 2 merupakan hasil rata-rata nilai dari task yang gagal dikerjakan oleh 5 responden kategori trampil. Rata-rata nilai yang dihasilkan adalah sebesar $21 \%$. Rata-rata nilai dari task yang berhasil dikerjakan oleh responden kategori pemula dapat dilihat pada Tabel 3.

Tabel 3. Hasil Data Task Berhasil Responden Kategori Pemula

\begin{tabular}{|c|c|c|c|c|}
\hline $\begin{array}{c}\text { Kode } \\
\text { Responden }\end{array}$ & $\begin{array}{c}\text { Jumlah Task } \\
\text { yang Berhasil } \\
\text { dikerjakan }\end{array}$ & Total Tugas & Berhasil & \multirow{2}{*}{ Rata-rata } \\
\hline R6 & 20 & 29 & 68,96 & \multirow{2}{*}{$64 \%$} \\
\hline R7 & 19 & 29 & 65,51 & \multirow{2}{*}{ (19 } \\
\hline R8 & 17 & 29 & 58,62 & \\
\hline R9 & 17 & 29 & 58,62 & \\
\hline R10 & 20 & 29 & 68,96 & \\
\hline
\end{tabular}

Tabel 3 merupakan hasil rata-rata nilai dari task yang berhasil dikerjakan oleh 5 responden kategori pemula. Rata-rata nilai yang dihasilkan adalah sebesar $64 \%$. Rata-rata nilai dari task yang gagal dikerjakan oleh responden kategori pemula dapat dilihat pada Tabel 4.

Tabel 4. Hasil Data Task Gagal Responden Kategori Pemula

\begin{tabular}{|c|c|c|c|c|}
\hline $\begin{array}{c}\text { Kode } \\
\text { Responden }\end{array}$ & $\begin{array}{c}\text { Jumlah Task } \\
\text { yang Berhasil } \\
\text { dikerjakan }\end{array}$ & Total Tugas & Berhasil & \multirow{2}{*}{ Rata-rata } \\
\hline R6 & 9 & 29 & 31,03 & \multirow{2}{*}{$36 \%$} \\
\hline R7 & 10 & 29 & 34,48 & \\
\hline R8 & 12 & 29 & 41,37 & \\
\hline R9 & 12 & 29 & 41,37 & \\
\hline R10 & 9 & 29 & 31,03 & \\
\hline
\end{tabular}

Tabel 4 merupakan hasil rata-rata nilai dari task yang berhasil dikerjakan oleh 5 responden kategori pemula. Rata-rata nilai yang dihasilkan adalah sebesar $64 \%$.

b) Efesiensi

Pengukuran efisiensi dilakukan dengan memperhitungkan rata-rata waktu dengan satuan detik dalam mengerjakan 29 task yang diberikan oleh 10 responden. Responden telah ditentukan dengan dua kategori yaitu trampil dan pemula. Hasil data lama waktu pengerjaan berdasarkan responden kategori trampil dapat dilihat pada Tabel 5.

Tabel 5. Pengolahan Data Efisiensi Responden Kategori Trampil

\begin{tabular}{|c|c|c|c|c|c|c|}
\hline \multirow{2}{*}{$\begin{array}{c}\text { Task } \\
\text { Scenario }\end{array}$} & \multicolumn{7}{|c|}{ Kode Responden } & \multirow{2}{*}{ Rata-rata } \\
\cline { 2 - 6 } TS1 & 7 & 6 & $\mathbf{R 2}$ & $\mathbf{R 4}$ & $\mathbf{R 5}$ & \\
\hline TS2 & 46 & 46 & 56 & 63 & 90 & 6.4 \\
\hline TS3 & 33 & 81 & 136 & 121 & 157 & 105.6 \\
\hline TS4 & 22 & 20 & 28 & 19 & 38 & 25.4 \\
\hline TS5 & 41 & 36 & 54 & 56 & 48 & 47 \\
\hline TS6 & 9 & 8 & 14 & 10 & 8 & 9.8 \\
\hline TS7 & 20 & 20 & 23 & 35 & 71 & 33.8 \\
\hline TS8 & 6 & 7 & 7 & 8 & 7 & 7 \\
\hline TS9 & 8 & 12 & 16 & 22 & 14 & 14.4 \\
\hline TS10 & 23 & 13 & 30 & 19 & 18 & 20.6 \\
\hline TS11 & 13 & 11 & 15 & 17 & 21 & 15.4 \\
\hline TS12 & 17 & 19 & 18 & 21 & 17 & 18.4 \\
\hline TS13 & 20 & 27 & 38 & 18 & 18 & 24.2 \\
\hline TS14 & 14 & 15 & 21 & 15 & 13 & 15.6 \\
\hline TS15 & 8 & 6 & 19 & 36 & 8 & 15.4 \\
\hline TS16 & 17 & 57 & 27 & 96 & 28 & 45 \\
\hline
\end{tabular}




\begin{tabular}{|c|c|c|c|c|c|c|}
\hline TS17 & 11 & 13 & 24 & 34 & 17 & 19.8 \\
\hline TS18 & 8 & 6 & 12 & 11 & 6 & 8.6 \\
\hline TS19 & 18 & 21 & 18 & 37 & 20 & 22.8 \\
\hline TS20 & 7 & 6 & 9 & 6 & 7 & 7 \\
\hline TS21 & 15 & 14 & 25 & 27 & 20 & 20.2 \\
\hline TS22 & 37 & 64 & 84 & 67 & 99 & 70.2 \\
\hline TS23 & 8 & 7 & 14 & 11 & 10 & 10 \\
\hline TS24 & 8 & 7 & 10 & 11 & 7 & 8.6 \\
\hline TS25 & 25 & 42 & 21 & 42 & 45 & 35 \\
\hline TS26 & 9 & 25 & 18 & 28 & 29 & 21.8 \\
\hline TS27 & 50 & 45 & 46 & 53 & 43 & 47.4 \\
\hline TS28 & 39 & 97 & 204 & 133 & 90 & 112.6 \\
\hline TS29 & 15 & 10 & 20 & 16 & 17 & 15.6 \\
\hline \multicolumn{7}{|c|}{ Rata-rata } \\
\hline
\end{tabular}

Tabel 5 merupakan hasil pengolahan data untuk mengukur variabel efisiensi. Hasil yang terdapat pada Tabel 5 dapat diketahui bahwa rata-rata waktu untuk mengerjakan setiap task bagi responden kategori trampil adalah 30 detik. Hasil data lama waktu pengerjaan berdasarkan responden kategori pemula dapat dilihat pada Tabel 6.

Tabel 6. Pengolahan Data Efisiensi Responden Kategori Pemula

\begin{tabular}{|c|c|c|c|c|c|c|}
\hline \multirow{2}{*}{$\begin{array}{c}\text { Task } \\
\text { Scenario }\end{array}$} & \multicolumn{5}{|c|}{ Kode Responden } & \multirow{2}{*}{ Rata-rata } \\
\hline & R6 & R7 & $\mathbf{R 8}$ & $\mathbf{R 9}$ & R10 & \\
\hline TS1 & 8 & 7 & 6 & 5 & 6 & 6.4 \\
\hline TS2 & 203 & 237 & 262 & 207 & 201 & 222 \\
\hline TS3 & 30 & 41 & 68 & 85 & 50 & 54.8 \\
\hline TS4 & 64 & 50 & 31 & 52 & 24 & 44.2 \\
\hline TS5 & 212 & 129 & 113 & 130 & 114 & 139.6 \\
\hline TS6 & 19 & 18 & 14 & 12 & 14 & 15.4 \\
\hline TS7 & 220 & 162 & 243 & 134 & 122 & 176.2 \\
\hline TS8 & 29 & 13 & 7 & 7 & 6 & 12.4 \\
\hline TS9 & 25 & 16 & 21 & 14 & 14 & 18 \\
\hline TS10 & 32 & 21 & 25 & 18 & 24 & 24 \\
\hline TS11 & 27 & 23 & 31 & 15 & 15 & 22.2 \\
\hline TS12 & 27 & 26 & 29 & 22 & 22 & 25.2 \\
\hline TS13 & 55 & 90 & 29 & 46 & 52 & 54.4 \\
\hline TS14 & 15 & 21 & 19 & 14 & 12 & 16.2 \\
\hline TS15 & 39 & 22 & 16 & 29 & 32 & 27.6 \\
\hline TS16 & 19 & 31 & 38 & 54 & 28 & 34 \\
\hline TS17 & 45 & 58 & 33 & 39 & 14 & 37.8 \\
\hline TS18 & 20 & 10 & 9 & 18 & 9 & 13.2 \\
\hline TS19 & 96 & 59 & 34 & 35 & 29 & 50.6 \\
\hline TS20 & 6 & 17 & 11 & 9 & 7 & 10 \\
\hline TS21 & 14 & 21 & 26 & 12 & 29 & 20.4 \\
\hline TS22 & 133 & 110 & 137 & 120 & 81 & 116.2 \\
\hline TS23 & 22 & 15 & 10 & 10 & 9 & 13.2 \\
\hline TS24 & 9 & 16 & 9 & 10 & 12 & 11.2 \\
\hline TS25 & 43 & 70 & 69 & 68 & 39 & 57.8 \\
\hline TS26 & 92 & 61 & 41 & 27 & 43 & 52.8 \\
\hline TS27 & 85 & 75 & 61 & 58 & 72 & 70.2 \\
\hline TS28 & 150 & 174 & 136 & 104 & 135 & 139.8 \\
\hline TS29 & 85 & 36 & 21 & 15 & 19 & 35.2 \\
\hline \multicolumn{6}{|c|}{ Rata-rata } & 52 \\
\hline
\end{tabular}

Tabel 6 merupakan hasil pengolahan data dengan teknik Performance Measurement. Pengolahan data yang dilakaukan untuk mengukur variabel efisiensi. Hasil yang terdapat pada 
Tabel 6 dapat diketahui bahwa rata-rata waktu untuk mengerjakan setiap task bagi responden kategori pemula adalah 30 detik.

\section{b. Retrospective Think Aloud}

Bagian ini menampilkan hasil pengujian menggunakan teknik Retrospective Think Aloud. Pengujian dengan menggunakan teknik Retrospective Think Aloud digunakan untuk mengukur variabel kepuasan pengguna saat menggunakan aplikasi Simalu. Hasil pengujian menggunakan teknik Retrospective Think Aloud dengan responden kategori trampil dapat dilihat pada Tabel 7.

Tabel 7. Hasil Data Retrospective Think Aloud Kategori Trampil

\begin{tabular}{|c|c|c|}
\hline KR & Masalah/Kesulitan yang dialami & Kritik dan Saran yang diberikan \\
\hline R1 & $\begin{array}{l}\text { 1. Pengguna tidak mengetahui } \\
\text { pada fitur setor langsung dapat } \\
\text { terhubung ke google maps untuk } \\
\text { mencari rute bank sampah yang } \\
\text { dipilih. } \\
\text { 2. Kesulitan mencari fitur FAQ. } \\
\text { 3. Instagram Simalu tidak dapat } \\
\text { dibuka. } \\
\text { 4. Kesulitan menemukan slider } \\
\text { agar dapat terhubung ke website } \\
\text { Simalu. }\end{array}$ & $\begin{array}{l}\text { 1. } \begin{array}{l}\text { Berikan tambahan informasi } \\
\text { pemberitahuan verifikasi secara } \\
\text { langsung. }\end{array} \\
\text { 2. Sebaiknya ketika akun belum } \\
\text { terverifikasi pengguna tidak dapat } \\
\text { login terlebih dahulu. } \\
\text { 3. Verifikasi akun sebaiknya lewat sms } \\
\text { dengan memberikan kode unik untuk } \\
\text { memperudah pengguna. } \\
\text { 4. Sebaiknya ditambahkan fitur edit foto. }\end{array}$ \\
\hline
\end{tabular}

Tabel 7 merupakan hasil data dari responden kategori trampil. Hasil data diperoleh dengan menggunakan teknik Retrospective Think Aloud. Hasil data pengujian menggunakan teknik Retrospective Think Aloud dengan responden kategori pemula dapat dilihat pada Tabel 8 sebagai berikut.

Tabel 8. Hasil Data Retrospective Think Aloud Kategori Pemula

\begin{tabular}{|c|c|c|}
\hline KR & Masalah/Kesulitan yang dialami & Kritik dan Saran yang diberikan \\
\hline R6 & $\begin{array}{l}\text { 1. Salah melakukan daftar akun. } \\
\text { 2. Kesulitan mencari fitur ubah kata } \\
\text { sandi. } \\
\text { 3. Kesulitan mencari alamat yang } \\
\text { sesuai pada fitur jemput sampah. } \\
\text { 4. Kesulitan mencari detail riwayat } \\
\text { transaksi. } \\
\text { 5. Kesulitan menemukan bank } \\
\text { sampah terdekat. }\end{array}$ & $\begin{array}{l}\text { 1. Sebaiknya fitur untuk mendafatar lebih } \\
\text { ditonjolkan } \\
\text { 2. Peringatan untuk mendaftar ketika } \\
\text { belum mepunyai akun fontnya lebih } \\
\text { diperbesar. } \\
\text { 3. Sebaiknya berikan tambahan } \\
\text { peringatan agar pengguna } \\
\text { memverifikasi akun terlebih dahulu. } \\
\text { 4. Sebaiknya verifikasi akun jangan } \\
\text { melalui email tolong buat agar lebih } \\
\text { mudah melakukan verifikasi. }\end{array}$ \\
\hline
\end{tabular}

Tabel 8 merupakan hasil data dari responden kategori pemula. Hasil data diperoleh dengan menggunakan teknik Retrospective Think Aloud.

\subsection{Analisis Hasil Pengujian}

Bagian ini menjelaskan analisis hasil pengujian yang telah dilakukan dengan menggunakan teknik Performance Measurement dan Retrospective Think Aloud. Analisis dilakukan untuk memberi penjelasan lebih dalam mengenai maksud dari hasil data yang telah diperoleh untuk mendapatkan kesimpulan.

a. Performance Measurement

Hasil pengujian dengan teknik Performance Measurement akan dilakukan analisis hasil. Hasil yang didapat adalah berupa tingkat efektifitas dan efisiensi pada aplikasi. Hasil analisis dari data Performance Measurement yang telah diperoleh adalah sebagai berikut. 
a)

Efektifitas

Hasil berdasarkan pengolahan data yang telah di peroleh dari responden kategori trampil menunjukan bahwa rata-rata responden berhasil mengerjakan task yaitu sebesar $79 \%$, sedangkan rata-rata responden gagal mengerjakan task yaitu sebesar $21 \%$. Adanya kegagalan yang dialami responden menunjukan bahwa aplikasi Simalu memiliki kualitas yang belum dapat dikatakan efektif karena responden masih belum dapat sepenuhnya berhasil menyelesaikan task yang diberikan. Hasil dari pengolahan data menunjukan bahwa kegagalan terjadi pada saat responden mengerjakan task 2, 3, 5, 15, 17, 22, 25, 26, 27 dan 28.

Hasil berdasarkan pengolahan data yang telah di peroleh dari responden kategori pemula menunjukan bahwa rata-rata responden berhasil mengerjakan task yaitu sebesar $64 \%$, sedangkan rata-rata responden gagal mengerjakan task yaitu sebesar $36 \%$. Adanya kegagalan yang dialami responden menunjukan bahwa aplikasi Simalu memiliki kualitas yang belum dapat dikatakan efektif karena responden masih belum dapat sepenuhnya berhasil menyelesaikan task yang diberikan. Hasil dari pengolahan data menunjukan bahwa kegagalan yang terjadi pada saat responden mengerjakan task 2, 3, 5, 7, 15, 16, 17, 22, 25, 26, 27, 28, dan 29. Kegagalan yang dialami oleh responden dapat dijadikan acuan untuk memperbaiki aplikasi Simalu agar kedepannya meminimalisir kegagalan yang akan dialami responden saat menggunakan aplikasi.

b)

\section{Efesiensi}

Hasil berdasarkan pengolahan data efisiensi yang telah diperoleh dari responden kategori trampil rata-rata waktu untuk mengerjakan setiap task adalah 30 detik, berdasarkan rata-rata yang diperoleh menunjukan bahwa task 2, 3, 5, 22, 25, 27, dan 28 merupakan task yang membutuhkan waktu paling lama untuk diselesaikan dan mempunyai nilai efisiensi yang tinggi jika dibandingkan dengan nilai efisiensi untuk task lainnya, sehingga untuk task 2, 3, 5, 22, 25, 27, dan 28 masih belum memiliki kualitas yang dapat dikatakan efisien saat digunakan oleh responden kategori trampil karena responden membutuhkan waktu yang lama untuk menyelesaikan task tersebut.

Hasil berdasarkan pengolahan data efisiensi yang telah diperoleh dari responden kategori pemula rata-rata waktu untuk mengerjakan setiap task adalah 52 detik, berdasarkan rata-rata yang diperoleh menunjukan bahwa task 2, 5, 7, 13, 22, 25, 27, dan 28 merupakan task yang membutuhkan waktu paling lama untuk diselesaikan dan mempunyai nilai efisiensi yang tinggi jika dibandingkan dengan nilai efisiensi untuk task lainnya, sehingga untuk task 2, 3, 4, 5, 7, 19, 22, 25, 27, dan 28 masih belum memiliki kualitas yang dapat dikatakan efisien saat digunakan oleh responden kategori trampil karena responden membutuhkan waktu yang lama untuk menyelesaikan task tersebut.

\section{b. Retrospective Think Aloud}

Hasil berdasarkan analisis rekapan kesulitan ataupun masalah yang dihadapi oleh responden dapat disimpulkan bahwa didapati responden kategori trampil mengalami kesulitan maupun masalah pada 12 fitur saat menggunakan aplikasi Simalu, sedangkan responden kategori pemula mengalami kesulitan maupun masalah pada 13 fitur. Adanya masalah atau kesulitan yang ditemukan membuat responden baik kategori trampil maupun pemula menjadi merasa kurang puas saat menggunakan aplikasi Simalu, ini dikarenakan fitur-fitur yang ada pada aplikasi sulit ditemukan oleh responden karena baik dari tata letak yang sulit ditemukan maupun icon yang dinilai kurang sesuai dengan isinya dan ambigu.

Hasil berdasarkan analisis rekapan saran dari responden dapat diketahui bahwa dari responden kategori trampil memberikan saran pada 25 fitur yang ada pada aplikasi Simalu, sedangkan responden kategori pemula memberikan saran pada 20 fitur. Saran yang diberikan oleh responden akan dijadikan sebagai bahan rekomendasi untuk memperbaiki aplikasi agar lebih baik lagi dan memenuhi kepuasan pengguna saat menggunakan aplikasi Simalu.

\subsection{Rekomendasi Perbaikan}

Rekomendasi yang diberikan berupa rancangan mockup. Dasar yang digunakan untuk membuat rekomendasi perbaikan menggunakan teori Eight Golden Rules oleh Benn Shneiderman dan hasil pengujian usability yang telah dilakukan. Desain perbaikan aplikasi Simalu yang telah dibuat akan ditampilkan sebagai berikut. 
a. Halaman Masuk dan Daftar

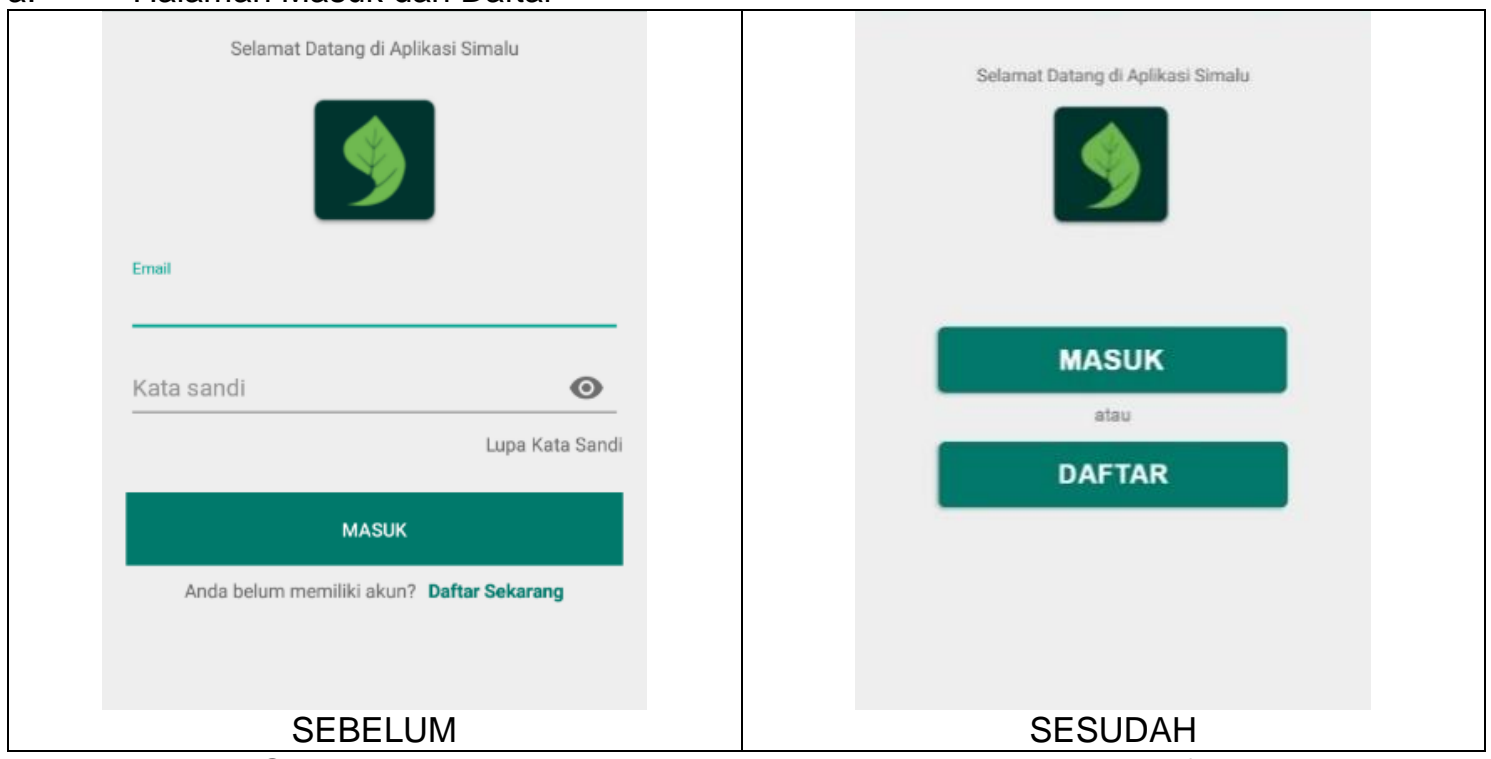

Gambar 2. Perbandingan Tampilan Halaman Masuk dan Daftar

Gambar 2 merupakan perbandingan tampilan halaman masuk dan daftar. Tampilan sebelah kiri merupakan tampilan sebelum dilakukan perubahan dan tampilan kanan sesudah dilakukan perubahan. Perbaikan yang dilakukan yaitu dengan melakukan penyederhanaan tampilan.

b. Halaman Beranda

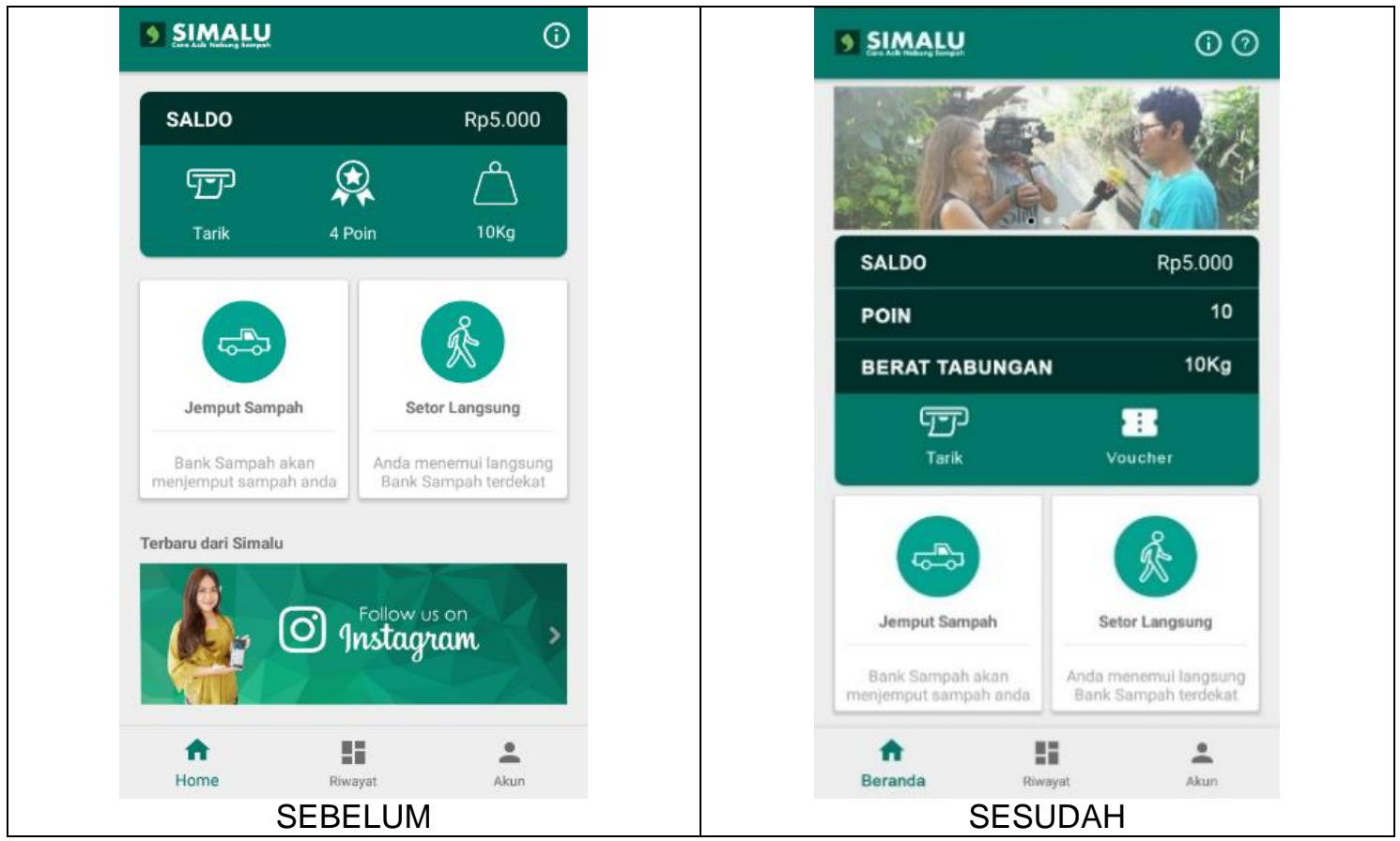

Gambar 3. Perbandingan Tampilan Halaman Beranda

Gambar 3 merupakan perbandingan tampilan halaman utama menu beranda. Tampilan sebelah kiri merupakan tampilan sebelum dilakukan perubahan dan tampilan kanan sesudah dilakukan perubahan. Perbaikan yang dilakukan yaitu dengan melakukan perbuahan bahasa atau istilah serta penyederhanaan dan penyesuaian tata letak fitur. 
C.

Halaman Riwayat

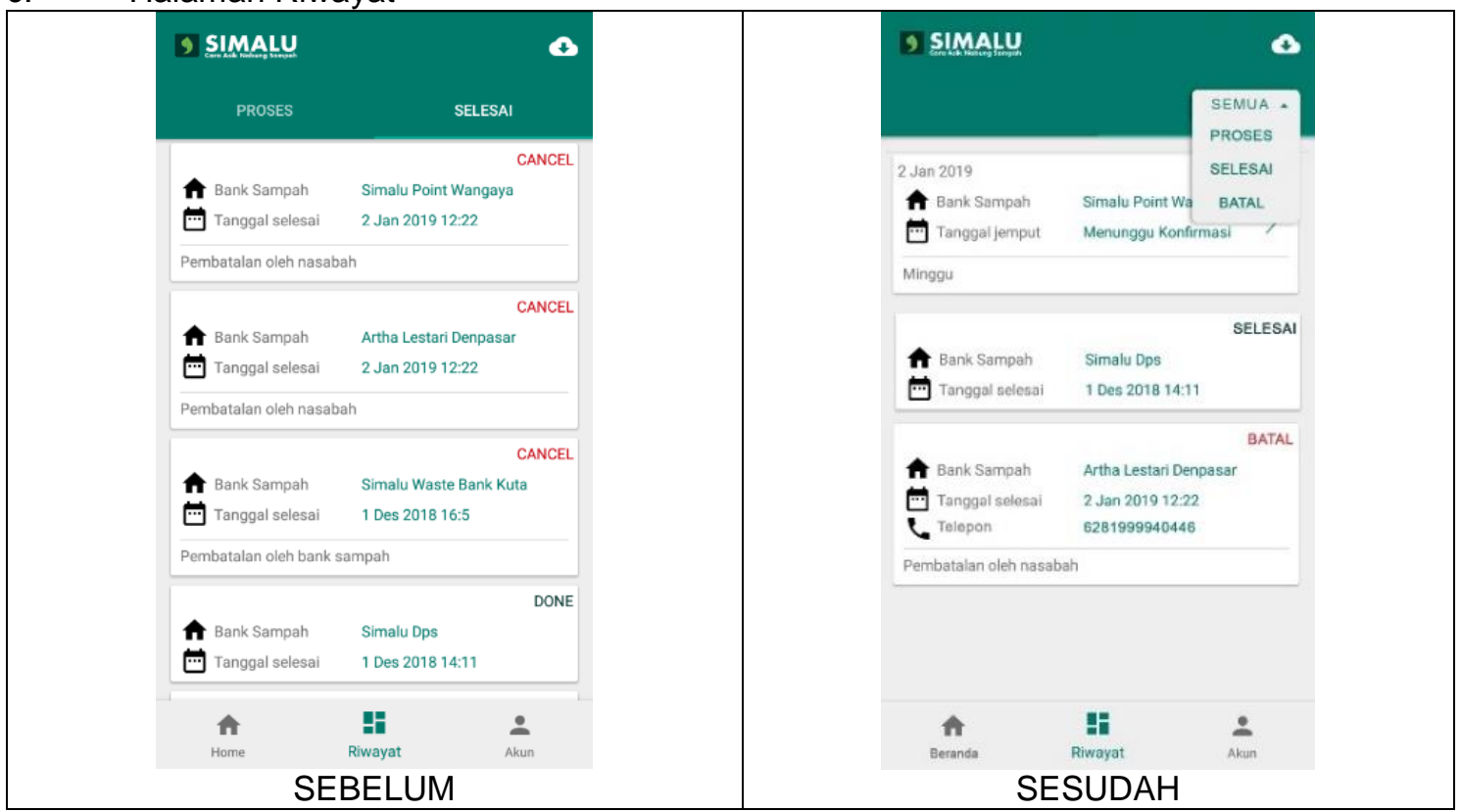

Gambar 5. Perbandingan Tampilan Halaman Riwayat

Gambar 5 merupakan perbandingan tampilan halaman utama menu riwayat. Tampilan sebelah kiri merupakan tampilan sebelum dilakukan perubahan dan tampilan kanan sesudah dilakukan perubahan. Perbaikan yang dilakukan yaitu dengan melakukan penyederhanaan fitur serta melakukan perubahan bahasa atau istilah.

d. Halaman Akun

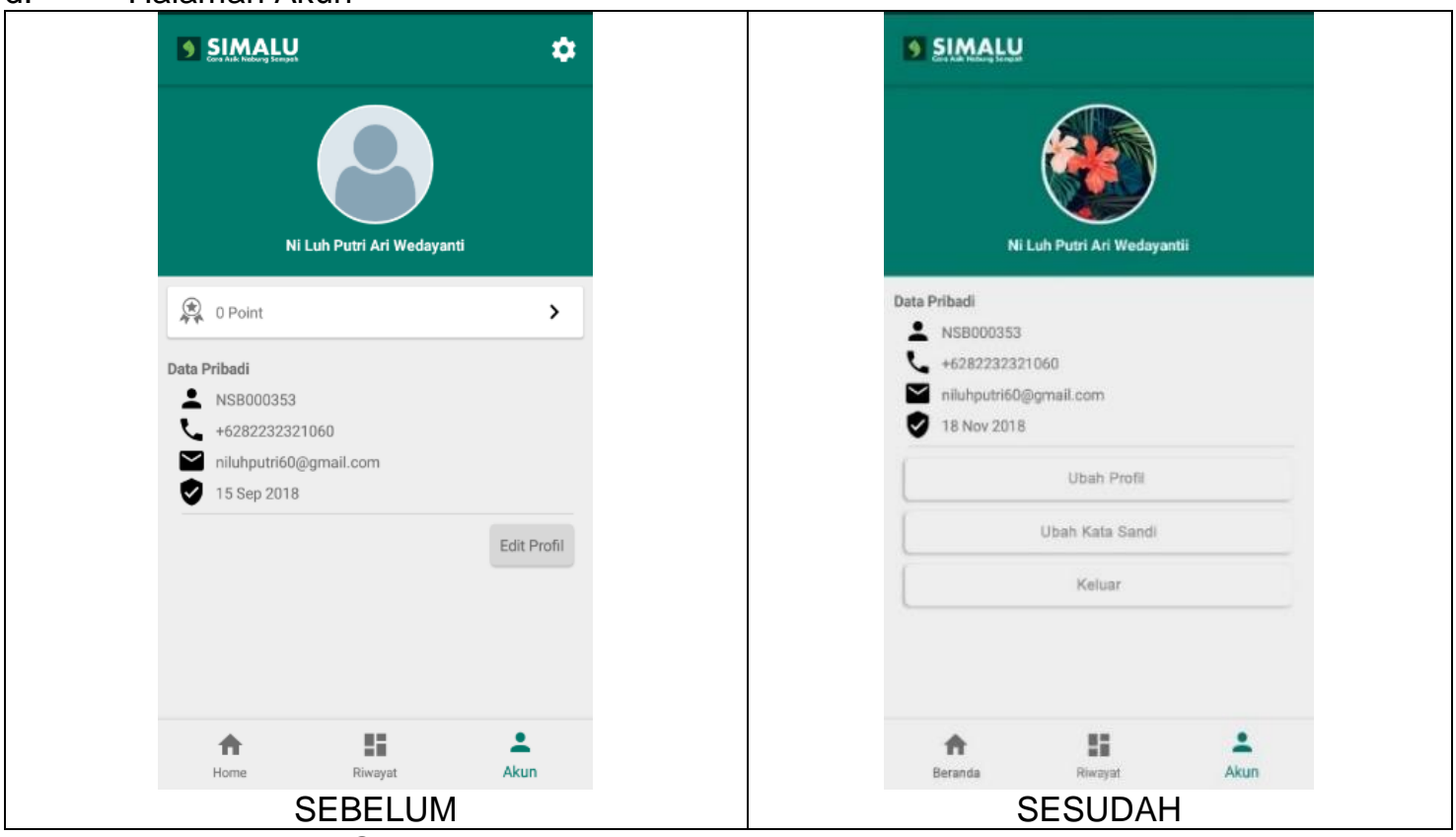

Gambar 6. Perbandingan Tampilan Halaman Akun

Gambar 6 merupakan perbandingan tampilan halaman utama menu akun. Tampilan sebelah kiri merupakan tampilan sebelum dilakukan perubahan dan tampilan kanan sesudah dilakukan perubahan. Perbaikan yang dilakukan yaitu dengan melakukan perubahan bahasa atau istilah serta penyederhanaan dan penyesuaian tata letak fitur. 


\section{Kesimpulan}

Penerapan metode Usability Testing dilakukan dengan cara mengukur bagaimana keefektifitasan, keefisiensian, dan kepuasan pengguna dalam menggunakan aplikasi Simalu. Efektifitas dapat dihitung berdasarkan keberhasilan dan kegagalan task yang telah dikerjakan oleh responden. Efisiensi dapat dihitung berdasarkan lama waktu pengerjaan yang dilakukan oleh responden dalam menyelesaikan task yang diberikan. Kepuasan didapat dengan cara merekam aktifitas responden ketika sedang mengerjakan sejumlah task yang diberikan. Video hasil rekaman yang ada diputarkan kembali untuk mendorong ingatan responden mengenai apa yang telah dikerjakan sehingga, dapat memberikan informasi kesalahan, keluhan maupun saran perbaikan. Hasil berdasarkan pengujian menunjukkan bahwa aplikasi Simalu memiliki kualitas yang belum dapat dikatakan efektif, efisien dan memenuhi kepuasan pengguna. Aplikasi Simalu belum dapat memberikan pemahaman yang maksimal melalui tampilan yang ada baik kepada responden kategori tampil maupun pemula. Hal tersebut menyebabkan responden mengalami kesulitan dalam mencapai tujuannya untuk mencari informasi yang diinginkan dan membuat kinerja responden juga menjadi tidak maksimal dalam menggunakan aplikasi. Perbaikan rekomendasi desain yaitu dengan melakukan penambahan, penyederhanaan dan penyesuaian tata letak fitur serta konsistensi penggunaan bahasa dan istilah. Rekomendasi yang telah dibuat diharapkan dapat menjadikan aplikasi Simalu menjadi efektif dan efisien saat digunakan agar aplikasi lebih baik lagi untuk memenuhi kepuasan pengguna.

\section{Daftar Pustaka}

[1] M. G. Arsawiguna, A. A. K. Agung, C. Wiranatha, dan K. S. Wibawa, "Rancang Bangun Aplikasi Game Tajen Berbasis Android menggunakan Artificial Intelligence," Lontar Komputer, vol. 6, no. 2, hal. 84-95, 2015.

[2] R. H. Y. Fung, D. K. W. Chiu, E. H. T. Ko, K. K. W. Ho, dan P. Lo, "Heuristic Usability Evaluation of University of Hong Kong Libraries' Mobile Website," Journal of Academic Librarianship, vol. 42, no. 5, hal. 581-594, 2016.

[3] I. P. P. Andika, P. A. Bayupati, dan N. K. A. Wirdiani, "Rancang Bangun Aplikasi Pendeteksi Tipe dan Nilai Resistor Berbasis Android," Lontar Komputer, vol. 6, no. 1, hal. 529-540, 2015.

[4] S. R. Wardhana, D. Purwitasari, dan S. Rochimah, "Analisis Sentimen pada Review Pengguna Aplikasi Mobile untuk Evaluasi Faktor Usability," Jurnal Sistem dan Informatika, vol. 11, no. 1, hal. 128-136, 2016.

[5] H. Hoehle dan V. Venkatesh, "Mobile Application Usability: Conceptualization and Instrument Development," MIS Quarterly, vol. 39, no. 2, hal. 435-472, 2015.

[6] M. Yudha, P. Mahendra, I. N. Piarsa, dan D. P. Githa, "Geographic Information System of Public Complaint Testing Based on Mobile Web (Public Complaint)," Lontar Komputer, vol. 9, no. 2, hal. 95-103, 2018.

[7] A. A. K. Oka Sudana, I. W. G. Mayun Kepakisan, dan N. K. Dwi Rusjayanthi, "Implementation of Tree Structure and Recursive Algorithm for Balinese Traditional Snack Recipe on Android Based Application," International Journal of Interactive Mobile Technologies, vol. 10, no. 4, hal. 43-47, 2016.

[8] D. H. Syaifullah, M. A. Puspasari, dan A. Hanifah, "Analisis User Experience pada Penggunaan Aplikasi Mobile Jakarta Smart City," Prosiding SNTI dan SATELIT 2017, vol. 2017, no. 10, hal. 217-232, 2017.

[9] R. A. Murdiono, H. Tolle, dan A. P. Kharisma, "Evaluasi User Experience pada Aplikasi Mobile Penjualan Tiket Online," Jurnal Pengembangan Teknologi Informasi dan IImu Komputer, vol. 2, no. 5, hal. 2078-2085, 2018.

[10] M. D. Fahmi, H. M. Az-zahra, dan R. K. Dewi, "Perbaikan Usability Aplikasi Pemesanan Tiket Bioskop Menggunakan Metode Usability Testing dan USE Questionnaire," Jurnal Pengembangan Teknologi Informasi dan IImu Komputer, vol. 2, no. 12, hal. 6653-6660, 2018. 